\title{
A RELAÇÃO ENTRE TRABALHO E SAÚDE MENTAL EM PROFESSORES UNIVERSITÁRIOS SUBSTITUTOS
}

The relationship between work and mental health in temporary lecturers

La relation entre le travail et la santé mentale des professeurs universitaires adjoints

La relación entre trabajo y salud mental en profesores universitarios sustitutos

ORCID: http://orcid.org/0000-0002-0631-3812

Centro Universitário Maurício de Nassau, Campina Grande, Paraíba Brasil.

Graduada em Psicologia.

Carina Barata Cavalcanti ${ }^{2}$

ORCID: https://orcid.org/0000-0001-9382-8197

Centro Universitário Maurício de Nassau, Campina Grande, Paraíba, Brasil.

Graduada em Psicologia.

Eduardo Breno Nascimento Bezerra ${ }^{3}$

ORCID: http://orcid.org/0000-0001-6629-9306

Universidade Federal do Tocantins, Miracema, Tocantins Brasil. Doutorando em Psicologia pela Universidade Federal do Rio Grande do Norte, Brasil.

Bruno Medeiros ${ }^{4}$

ORCID: http://orcid.org/0000-0002-7143-8830 Centro Universitário Maurício de Nassau, Campina Grande, Paraíba, Brasil. Doutor em Psicologia pela Universidade de Cambridge, Reino Unido.

\section{Resumo}

A presente pesquisa teve como objetivo identificar a relação entre trabalho e a saúde mental dos docentes universitários substitutos, levando em consideração as condições e a organização do trabalho presente no contexto universitário. A pesquisa, de abordagem qualitativa foi realizada com 11 professores que atuam como substitutos em duas universidades públicas. A coleta de dados se deu por meio de uma entrevista semiestruturada. Após a análise das entrevistas, constatou- se que os fatores que mais causam sofrimento e contribuem para o adoecimento dos professores substitutos, se relacionam com a organização do trabalho, e dizem respeíto a distribuição de carga horária de trabalho entre efetivos e substitutos, a baixa remuneração e a falta de autonomia para decidirem questões da execução do serviço. Em decorrência da baixa remuneração, muitos professores substitutos acabam assumindo atividades em outras instituições (como docente ou não) para complementar a renda pessoal e/ou familiar. Essa dupla (ou tripla) jornada de trabalho acaba repercutindo nas condições de saúde desses trabalhadores, deixandoos mais propensos ao adoecimento físico e mental. Porém, percebeu-se que o fato de estarem em sala de aula, gera um sentimento de realização nos docentes, sendo a principalmente fonte de prazer no trabalho.

Palavras-chave: Professores substitutos; Adoecimento psíquico; Saúde mental.

\footnotetext{
${ }^{1}$ paulac.tibaes@gmail.com

2 carinabcavalcanti@gmail.com

3 eduardobreno@hotmail.com

${ }^{4}$ brunojpa@hotmail.com
} 


\begin{abstract}
The present study aimed to identify the relationship between work and mental health of temporary lecturers, taking into consideration the work conditions and organization at universities. The research had a qualitative approach being developed with 11 professors, who were working in two public universities. Data was collected through a semi-structured interview. After analyzing the interviews, it was found that the factors which most contributed to professors illness and suffering were related to the organization of work, and to the distribution of workload between staff and the temporary lecturers as well as to the low remuneration and the lack of autonomy in deciding matters regarding the execution of their activities. Due to low remuneration, many temporary lecturers end up taking up activities in other institutions (as a professor or not) to supplement personal and / or family income. This double (or triple) workload ends up impacting the health conditions of these workers, making them more prone to physical and mental illness. However, it was noticed that the fact of being in the classroom generates a sense of accomplishment in the temporary lecturers, being the main source of pleasure at work.
\end{abstract}

Keywords: Temporary lecturers; Mental illness; Mental Health.

\title{
Résumé
}

La présente étude avait pour but identifier la relation entre le travail et la santé mentale des professeurs universitaires adjoints, compte tenu de les conditions et l'organisation de ce genre de travail dans le context universitaire. Cette recherche, avec une approche qualitative, a été menée avec 11 professeurs qui agissent comme des adjoints dans deux universités publique. Les données ont été recueillies via d'entretiens semi-directives. Après l'analyse de les entretiens, il a été constaté que les facteurs qui causent le plus de souffrances et contribuent à la maladie des professeurs adjoints sont liés à l'organisation du travail et à la répartition de la charge de travail entre les personnels et les adjoints, et aussi en raison de la faible rémunération et le manque d'autonomie pour décider des questions relatives à la performance de leurs activités. À cause de la faible rémunération, des nombreux professeurs adjoints finissent par entreprendre des activités dans d'autres institutions (en tant qui sont professeurs ou non) pour compléter les revenus personnels et / ou familiaux. Cette double (ou triple) charge de travail finit par avoir un impact sur l'état de santé de ces travailleurs, les rendant plus vulnérables aux maladies physiques et mentales. Cependant, il a été remarqué que le fait d'être en classe suscite un sentiment de réussite chez les professeurs adjoints, qui est la principale source de plaisir au travail.

Mots clés: Professeurs adjoints; Maladie mentale; Santé mentale.

\section{Resumen}

La presente investigación tuvo el objetivo de identificar la relación entre trabajo y salud mental de los profesores universitarios sustitutos, considerando las condiciones y la organización del trabajo en el contexto universitario. La investigación, de abordaje cualitativa, fue realizada con 11 profesores que actúan como sustitivo en dos universidades públicas. Los datos fueron obtenidos por medio de una encuesta semiestructurada. Tras el análisis de las encuestas, constatamos que los factores que más causan enfermedad en eses profesores sustitutos se relacionan con la organización del trabajo, y dicen respecto a la distribución de la carga horaria de trabajo entre efectivos y sustitutos, la baja remuneración y la falta de autonomía para decidir cuestiones de la ejecución de sus actividades. En razón de los bajos sueldos, muchos profesores temporarios acaban asumiendo actividades en otras instituciones (como profesores o no) para complementar el sueldo personal y/o familiar. Esa dupla (o tripla) jornada de trabajo afecta las condiciones de salud de eses trabajadores, dejándolos más propensos a enfermedades físicas y mentales. Sin embargo, percibimos que la actividad docente resulta en un sentimiento de realización en los profesores, y esta es la principal fuente de satisfacción en el trabajo.

Palabras clave: Profesores sustitutos; Enfermedad psíquica; Salud mental.

INTRODUÇÃO

Atualmente, o papel do professor engloba muitos aspectos que vão além do processo de transmissão de conhecimento para o aluno (Gasparini, Barreto \& Assunção, 2005), pois sua função atinge também as variáveis invisíveis da aprendizagem, como valores, atitudes e crenças 
(Cericato, 2016). Além disso, esse profissional utiliza de suas concepções básicas como a cultura, o cotidiano e aquilo de ordem espontânea, para transmitir o saber pedagógico já existente (Gorzoni \& Davis, 2017), sendo o mediador entre os conhecimentos históricos acumulados e o aluno em desenvolvimento (Cericato, 2016; Vigotski, 1991). Tal prática visa formar, futuros cidadãos capazes de assumir seus papeis, promover mudanças e transformar a sociedade (Forattini \& Lucena, 2015).

Quando se trata dos professores no contexto universitário, suas tarefas são ampliadas para além da sala de aula. Além das atividades do ensino, os docentes possuem envolvimento com a gestão e o desenvolvimento da pesquisa e da extensão (Santino et al., 2017), buscando uma articulação maior com a comunidade em que estão inseridos (Gasparini et al., 2005). Além disso, devem balancear uma formação direcionada às competências essenciais para o mercado de trabalho e para o desenvolvimento de cidadãos críticos (Santos, Pereira \& Lopes, 2018).

De um modo geral, a função de professor universitário engloba dois tipos de contratos: os professores efetivos e os professores substitutos. A contratação dos substitutos passou a ser utilizada, sobretudo a partir de 1990, como uma estratégia das instituições de ensino superior público para compensar uma necessidade momentânea no quadro de docentes efetivos (Aquino et al., 2014).

Entretanto, essa modalidade de contratação de professores ocasionalmente tem se associado ao desgaste físico e psíquico. As condições de trabalho e a estrutura física, assim como a carga-horária, o tipo de prática, a autonomia, os turnos e horários de trabalho são fatores que tem influenciado diretamente na satisfação do trabalho desses profissionais quando comparados com a realidade de docentes efetivos (Santino, Tomaz \& Lucena, 2017).

Rates e Léda (2016) afirmam que um dos principais conflitos presentes no exercício da função de professor substituto está relacionado à fase de adaptação à instituição de ensino na qual o professor inicia sua atividades como temporário, pois em sua maioria esses profissionais se sentem deslocados e pouco acolhidos ao ingressarem no âmbito do trabalho. Aliado a esse sentimento, Braga e Oliveira (2015) destacam que esse vínculo de trabalho temporário pode suscitar sentimentos de insegurança e instabilidade em relação a questões futuras, sejam elas financeiras, de perspectivas profissionais ou até mesmo em relação ao projeto de vida de cada professor substituto. Além disso, as autoras destacam que esses professores tornam-se mais vulneráveis a possíveis adoecimentos devido à carga de trabalho ou por lecionarem em mais de uma instituição, restringindo muitas vezes sua vida ao trabalho.

Outro considerável fator dentro desse cenário é a desvalorização desses profissionais. A retração salarial dos docentes substitutos é um dos fenômenos emergentes dentro da conjuntura 
universitária e que têm sido cada vez mais alvo de críticas e mobilizações (Oliveira, Pereira \& Lima, 2017). A baixa remuneração se correlata com desprestígio social dessa profissão, e isso pode afetar a autoestima do sujeito, podendo gerar sofrimento e adoecimento (Cericato, 2016).

Mediante tal explanação e considerando a importância de se investigar as implicações do trabalho desenvolvido por professores substitutos, a Psicodinâmica do Trabalho tem se demonstrado como uma importante abordagem que busca entender a relação entre organização do trabalho e o funcionamento psíquico dos trabalhadores (Dejours, 1986; 2004a; 2012).

Dejours (1986) apresenta dois pontos essenciais para se entender a relação do trabalho com o funcionamento psíquico, sendo eles as condições do trabalho e a organização do trabalho. As condições do trabalho dizem respeito às condições físicas, químicas e biológicas existentes no contexto organizacional. A temperatura, pressão, as vibrações, os vapores, poeiras, micróbios e as bactérias são exemplos de condições as quais afetam diretamente o corpo do trabalhador. Já a organização do trabalho, relaciona-se à divisão das tarefas, desde o conteúdo até o modo de realizá-las, e à divisão dos homens, direcionada às relações humanas.

Desse modo, possuir um trabalho equilibrante não coloca questões relativas ao ambiente físico ou químico do trabalho, mas diz respeito, principalmente, à organização do próprio trabalho. Por esse motivo, Dejours, Dessors \& Desriaux (1993) destacam que ao colocar-se face a face o funcionamento psíquico e a organização do trabalho, descobre-se que certas organizações são perigosas para o equilíbrio psíquico. Entretanto, a organização do trabalho não é uma entidade todo-poderosa, "as pessoas não são fantoches manipulados por uma organização do trabalho marionetista" (Molinier, 2013, p. 86). Nesse sentido, o sujeito é compreendido como um ser único, portador de desejos e projetos enraizados na sua história singular e que, de acordo com suas características de personalidade, reage à realidade e as pressões organizacionais de maneira original (Dejours \& Abdoucheli, 1994).

$\mathrm{Na}$ perspectiva dejouriana, o trabalho se constitui como um espaço de ações de ajustamento, adaptação, reparação e reorganização que são constantes (Dejours, 2004a; 2012). Nesse sentido, o trabalho implica, do ponto de vista humano, no "engajamento do corpo, a mobilização da inteligência, a capacidade de refletir, de interpretar e de reagir às situações; é o poder de sentir, de pensar e de inventar" (Dejours, 2004b, p. 28). Assim, ao trabalhar, é preciso correr os riscos de se manifestar, mostrar o que se faz e dizer o que pensa. Para isso, os trabalhadores lançam mão de estratégias de enfrentamento, as quais são defesas utilizadas pelos trabalhadores para evitar o adoecimento mental, seja a nível individual ou coletivo (Dejours, 2013). 
Diante da vivência de especificidades da profissão de docentes substitutos, vê-se que estes profissionais são obrigados a acrescentar mais de si mesmo para realizar seu trabalho, obter mais resultados e fazer frente aos impedimentos colocados pela organização do trabalho. Além disso, sabe-se que este profissional tem pouca autonomia no trabalho, se comparado a profissionais efetivos, o que pode ser revertido em possível sofrimento ao encontrar inúmeras dificuldades na execução de suas tarefas (Rates \& Léda, 2016).

Entendendo que o docente universitário substituto também é submetido a regras institucionais, de produção e reprodução do sistema, e diante dos inúmeros casos de adoecimento por conta dessa atividade laboral (Oliveira, Pereira, \& Lima, 2017), ao baixo reconhecimento, a sobrecarga de trabalho e a discriminação sofrida em comparação aos demais profissionais, ressalta-se a importância em investigar o trabalho desses profissionais dentro das universidades, buscando compreender as relações desse trabalho com a saúde mental.

Nesta perspectiva, este artigo teve como objetivo identificar a relação entre trabalho e saúde mental dos docentes universitários substitutos, levando em consideração as condições e a organização do trabalho presente no contexto universitário. De modo específico, buscou-se ainda identificar os fatores que podem influenciar no adoecimento psíquico desses profissionais, e perceber as possíveis estratégias que vem sendo desenvolvidas por esses profissionais para evitar o adoecimento. A Psicodinâmica do Trabalho foi tomada nesse estudo como a principal abordagem teórica para permitir a análise e discussão dos dados encontrados.

\section{MATERIAIS E MÉTODOS}

A pesquisa é de enfoque qualitativo, do tipo descritiva-exploratória. A amostra envolveu 11 professores substitutos de duas instituições de ensino superior pública, uma estadual e outra federal, no Estado da Paraíba, Brasil. Oito docentes lecionam na área de humanas e três na área da saúde. Como critério de inclusão foi adotado o fato de estarem atuando como professores substitutos por pelo menos seis meses, considerando esse o tempo necessário para ter passado por pelo menos um semestre letivo completo. Os docentes que não atenderam a esse critério não participaram da pesquisa.

O instrumento utilizado para a coleta de dados foi uma entrevista do tipo semiestruturada, a qual permite uma flexibilidade a respeito dos atributos a serem investigados (Moré, 2015). Tal flexibilidade mostrou-se pertinenté para se entender o modo como os participantes vivenciam suas experiências como docentes substitutos, permitindo se expressarem e se colocarem no decorrer da entrevista, com indagações que se mantiveram 
direcionadas aos objetivos de investigação. As questões basearam-se em aspectos referentes as condições de trabalho, ao estado de saúde dos professores e as formas de enfrentamento por eles desenvolvidos.

A coleta de dados ocorreu de acordo com a disponibilidade dos participantes. Portanto, foram realizadas entrevistas tanto nas próprias instituições de ensino que os professores lecionavam, como em ambientes externos, a exemplo de shoppings, café e na própria casa dos participantes, conforme o desejo dos mesmos. Em todas as situações, um ou mais pesquisadores iam ao encontro do participante em horário e local acordados com os mesmos. Antes de iniciar as entrevistas, foi aplicado o Termo de Consentimento Livre e Esclarecido (TCLE), bem como o Termo de Autorização para Gravação de Voz. Em sequência, o questionário sociodemográfico, o qual foi manuseado pelos pesquisadores a fim de traçar o perfil dos participantes. O tempo médio das entrevistas foi de 35 minutos e todas foram gravadas e transcritas na íntegra.

Inicialmente, o procedimento optado para coleta dos dados foi o contato com algumas coordenações de diferentes cursos das instituições de ensino superior (IES), para levantar a existência de docentes substitutos e conseguir o contato dos docentes. Aliado a essa estratégia foi utilizada a técnica "bola de neve". Esta técnica consiste em entrevistar um participante que atenda aos critérios de inclusão da pesquisa e, ao final, solicita-se que ele indique alguém que se enquadre nos aspectos pedidos, seguindo assim até serem entrevistados o total de participantes da amostra (Vinuto, 2014). As entrevistas foram encerradas baseando-se no critério da saturação que, de acordo com Minayo (2006), consiste na suspensão de novos participantes quando o pesquisador percebe que os dados coletados já apresentam certa repetição ou redundância.

O procedimento de análise dos dados foi realizado por meio da análise de conteúdo temática proposta por Laville e Dionne (1999). Essa análise consiste em desmontar a estrutura e extrair os elementos desse conteúdo, tendo como finalidade facilitar a análise e a interpretação dos dados, possibilitando compreender sua significação. Devido a isso, todas as entrevistas foram relidas pelos pesquisadores para uma análise minuciosa das falas, buscando compreender o significado daquilo que foi dito pelos participantes. Cabe destacar que essa pesquisa foi fruto de um Trabalho de Conclusão de Curso no curso de Psicologia de uma instituição privada de ensino superior, e toda a pesquisa seguiu os aspectos éticos contidos na resolução do Conselho Nacional de Saúde (CNS) 466/2012, sendo aprovada pelo Comitê de Ética do Centro de Ensino Superior e Desenvolvimento (CEP/CESED) com o número de protocolo 


\section{RESULTADOS E DISCUSSÃO}

Antes da apresentação dos dados levantados nas entrevistas, cabe aqui destacar o perfil sócio demográfico dos participantes que compuseram a amostra da pesquisa. Dos 11 participantes, seis são do sexo feminino e cinco do sexo masculino, com idade que variaram entre 21 e 51 anos, com média de 35 anos. Uma amostra jovem, quando comparada com dados de outras pesquisas que encontraram a média de idade de 50 anos de professores universitários (Coêlho et al, 2016), o que aponta para o fato de que cada vez mais novos os professores estão se inserindo na carreira de magistério superior, a exemplo do participante com 21 anos que já iniciou sua jornada como professor substituto.

Seis dos participantes declararam ser casados ou estarem em união estável, os demais são solteiros, e cinco deles afirmaram terem filhos. Quanto a renda salarial, um participante afirmou receber até 2 salários mínimos, três deles receber até 4 salários e os demais que possuem uma renda superior aos 4 salários mínimos, sobretudo considerando os múltiplos vínculos empregatícios que possuem, como será destacado mais adiante.

No que se refere aos dados relativos à atividade docente, o tempo exercendo a atividade de professor variou de três a 25 anos, contudo quando se considera apenas o tempo de trabalho como professor substituto, o mesmo variou de sete meses a oito anos. A contratação de professores substitutos ocorre por um período de até dois anos, contudo cabe destacar que no caso dos participantes que afirmaram estar há mais de dois anos atuando como substitutos, são profissionais que estão no segundo, terceiro ou quarto contrato. Fato que é possível na instituição de ensino superior pública estadual, a qual permite que os professores possam ter contratos de substitutos consecutivos (desde que aprovados em processos seletivos), diferentemente do que ocorre nas instituições de ensino superior públicas federais, nas quais os professores após cada contrato como substituto, ficam impossibilitados de prestar nova seleção para substituto por um período de dois anos.

Quando se observa a carga horária de trabalho dos participantes, a mesma variou de $18 \mathrm{~h}$ e 40h semanais, dado também verificado em outras pesquisas com professores (Aquino et al, 2014). Contudo, nove dos onze participantes afirmaram que desenvolvem outra atividade (como docentes ou não) além do trabalho como substituto. Esse dado se apresenta como importante ponto que mais adiante será discutido nesse artigo, uma vez que demonstra o quanto esses professores estão mais vulneráveis a possíveis adóecimentos devido à carga de trabalho, por muitas vezes conciliarem mais de um vínculo empregatício (Braga \& Oliveira, 2015). 
A partir da análise das entrevistas, os resultados encontrados foram categorizados em três categorias temáticas, que a seguir serão apresentadas e discutidas, são elas: condições $e$ organização do trabalho; saúde mental e adoecimento físico e psíquico; e estratégias defensivas.

\section{Condições e Organização do Trabalho}

Esta categoria reúne as referências dos entrevistados sobre as condições e organização do trabalho presente na atividade do professor substituto. Conforme destaca Dejours (1986) as condições do trabalho, diz respeito às condições físicas, químicas e biológicas existentes no contexto organizacional, e a organização do trabalho se relaciona com o conteúdo e o modo de realizar as tarefas, e com a divisão dos homens, direcionada às relações humanas, sendo pontos essenciais para se entender a relação do trabalho com o funcionamento psíquico.

Santino et al. (2017) destaca que quando relacionada com condições de trabalho insuficientes, a atividade laboral da docência leva ao aumento considerável de distúrbios na saúde do professor universitário, refletindo diretamente em seu trabalho. Contudo, entre os participantes verificou-se que as condições de trabalho foram apontadas como satisfatórias, como pode se identificar nas falas a seguir:

"Tenho um bom ambiente de trabalho. Eu acho que a instituição oferece uma boa estrutura. [...] eu me sinto satisfeito com o ambiente." (Entrevistado 11)

“[...] é totalmente adequado, hoje a gente tem normativas de saúde e segurança do trabalho que garantem isso, principalmente nas particulares. Aqui também, a instituição passou por uma reestruturação muito grande então, por exemplo, uma sala desse tamanho com ar-condicionado? No meu tempo, inimaginável!” (Entrevistado 1)

As falas demonstram que as condições de trabalho não são consideradas um fator negativo no trabalho docente dos substitutos. Nenhum entrevistado apresentou queixa sobre as condições estruturais do seu ambiente de trabalho, o que configura um fator positivo dentro do âmbito laboral do professor universitário substituto. Dados que, possivelmente podem estar relacionados aos projetos governamentais de aprimoração das universidades brasileiras, vivenciadas no início dos anos 2000, e que tiveram um impacto positivo, entre outros aspectos, na estrutura das salas de aulas, como destacado por um dos entrevistados.

Por outro lado, quando se verifica elementos da organização do trabalho docente foi possível identificar fatores de precarização estrutural do trabalho (Antunes, 2008) desses profissionais, a qual já se evidencia com o contrato de trabalho temporário. Esse contrato 
temporário se desdobra na perca de direitos trabalhistas e na intensificação da exploração do trabalho desses professores. Um fato muito citado pelos participantes da pesquisa diz respeito a divisão de carga horária e distribuição de disciplinas. Percebeu-se nos relatos que o docente substituto detém uma maior carga horária de trabalho em sala de aula quando comparado aos efetivos, assumindo mais disciplinas e com maior número de idas a universidade em diferentes turnos, conforme se verifica nas falas que seguem:

"Comparando com outras experiências profissionais, o que eu vejo de diferente é a sobrecarga, [...] os substitutos, no meu caso, dizendo por mim, eu percebo assim, que tem uma sobrecarga maior que a dos efetivos, então é algo que eu percebo sem sombra de dúvidas." (Entrevistado 05)

"A gente tem como professor substituto, uma carga horária de sala de aula bem mais elevada do que um professor que não é substituto, ai soma as outras atividades, as orientações de TCC [...] e isso sobrecarrega! " (Entrevistado 11)

Essa sobrecarga de trabalho está em grande medida atrelada a carga horária em sala de aula, mas também se reflete com o assumir de outras atividades como orientações de trabalho de conclusão de curso, como destacado por um dos participantes. Aliado a isso, soma-se o fato da pouca autonomia desses profissionais no que diz respeito à divisão de tarefas e escolha das disciplinas a serem ministradas, e que gera grande sentimento de insatisfação entre esses profissionais, conforme é possível perceber nos discursos a seguir:

"Os efetivos escolhem previamente as disciplinas que eles vão ministrar e há uma segunda reunião, que quem só participa são os substitutos. É nesse momento que nós decidimos: com o que sobrou, com o que os efetivos não escolheram!" (Entrevistado 6)

"Quando a gente vai começar o semestre, [...] a gente vai ver que as disciplinas dos efetivos já vêm escolhidas e a gente fica pra dividir entre nós as outras que eles não quiseram. [...] Eu acho isso um pouco injusto, de tipo eles já escolherem as disciplinas que eles quiserem e as que eles não querem, a gente divide. Eu não gosto disso." (Entrevistado 5)

"Quando o horário é lançado os efetivos... eles selecionam. E eles têm uma carga horária menor do que a nossa, então o que sobra vai para a gente. Então a gente tem que cobrir... os alunos precisam de aula." (Entrevistada 9)

A falta de autonomia e liberdade para escolha das disciplinas se apresenta como um ponto da organização do trabalho fortemente destacado por esses profissionais que causa insatisfação entre os mesmos. Nesse cenário, ocorre de muitos deles se verem obrigados a darem disciplinas e mobilizarem subjetivamente cada vez mais de si, para que possa conceber o real do seu trabalho (Dejours, 2012). 
Essa falta de autonomia se reflete ainda em outros aspectos inerentes ao vínculo de trabalho temporário, como a impossibilidade de realização de projetos de pesquisas e/ou extensão com o apoio institucional, como destaca um dos participantes:

"[...] A gente não tem direito a voto, eu não posso fazer um projeto de extensão, [...] se eu quiser fazer, eu tenho que ficar como colaborador de algum já existente, eu não posso assinar o projeto. [...] A gente literalmente não é gente. A gente é força de trabalho escrava barata, pra poder seguir os interesses dos representantes, somente." (Entrevistado 1)

A desigualdade na divisão de carga horária e falta de autonomia em decorrência da natureza do vínculo contratual geral uma insatisfação, angústia e sofrimento nesses profissionais. Dessa confrontação com o real do trabalho, surgem sentimentos de impotência, até mesmo de irritação, cólera ou ainda de decepção (Dejours, 2004), como fica claro nas falas acima. Ao comparar o trabalho do professor substituto com uma forma de trabalho escravo barato, o participante demonstra todo seu sentimento de descontentamento e irritação que atravessa o seu trabalho.

Esses dados se relacionam com outros estudos realizados com docentes pelo Brasil, como a pesquisa realizada com professores do magistério do curso de Pedagogia, em uma universidade pública de Belo Horizonte, que também apontaram as diferenças de tratamento entre efetivos e substitutos, sobretudo em relação à falta de autonomia (Vilela et al, 2013). E com a pesquisa realizada com professores universitários de uma instituição privada também em Belo Horizonte, a qual apresentou que os aspectos que menos geram satisfação no trabalho docente se relacionam à falta de liberdade de expressão, ao esgotamento profissional e a falta de reconhecimento pelo trabalho exercido (Martins, 2009).

Além desses fatores de carga horária e falta de autonomia destacados acima, os participantes argumentam que outro ponto que marca a diferenciação entre os professores substitutos e efetivos é a diferenciação de salários. Apesar de estarem submetidos as mesmas condições de trabalho, "somos todos professores, mas o salário é bem mais baixo" (Entrevistado 7).

E a situação dos docentes substitutos da instituição de ensino superior estadual se agrava ainda mais, pois não há remuneração/gratificação paga aos docentes por titulação, como destacam alguns dos participantes:

“Tem professores aqui que são doutores, são substitutos e recebem como graduados. Eu sou mestre, mas também recebo como graduado." (Entrevistado 6) 
"No meu caso eu sou doutor, mas lá eu não ganho como doutor, isso é um ponto negativo da atuação profissional [...]. Além dessa carga horária extensiva, exaustiva, um grande número de turmas que nós temos [...]. Por isso, tem uma rotatividade muito grande de professor substituto, em função disso aí, da questão salarial também." (Entrevistado 11)

Nesse cenário de baixos salários, verificou-se que dos 11 participantes da pesquisa, nove deles desenvolviam outra atividade para complementar a renda. Dos nove, seis atuavam como docentes em outras instituições de ensino (instituições de ensino superior privadas, cursos técnicos e escola de idiomas), e três atuavam como profissionais liberais. Cabe destacar o caso de um dos participantes da área da saúde que declarou além de atuar como professor substituto, também trabalha como professor em uma instituição de ensino privada e ainda desenvolve atividades como profissional liberal em consultório.

Esses fatores presentes nas condições de trabalho dos professores substitutos além de refletirem a precarização do trabalho dessa categoria profissional, são agentes influenciadores diretos na satisfação do trabalho (Aquino et al, 2014). E esse vínculo de trabalho temporário, além de acarretar nos professores substitutos sentimento de insegurança e instabilidade em relação a questões futuras, sejam elas financeiras, de perspectivas profissionais ou até mesmo em relação ao projeto de vida, leva esses professores a lecionarem em mais de uma instituição ou desenvolverem outra atividade para compensar o financeiro. O que demonstra o quanto esses professores estão mais vulneráveis a possíveis adoecimentos devido à sobrecarga de trabalho (Braga \& Oliveira, 2015).

Todos esses fatores presentes na organização de trabalho aos quais os professores substitutos estão submetidos, acabam por manter relações com a saúde mental desses profissionais, influenciando num possível adoecimento dessa categoria, pois conforme destaca Dejours (2004b), o trabalho nunca é neutro contribuindo ora para a saúde, ora pra o adoecimento psíquico.

Para Dejours (1986), quando a organização limita os desejos do trabalhador, dificulta a adaptação à sua função, atinge sua autonomia para decidir o melhor modo para executar seu trabalho, para expandir seus conhecimentos e quando o seu trabalho não está sendo reconhecido devidamente, o trabalhador pode vir a adoecer física ou mentalmente, pontos a serem apresentados na categoria a seguir. 


\section{Saúde mental e adoecimento}

Um dos fatores cruciais que podem vir a afetar a saúde dos trabalhadores é o modo como o trabalho está organizado (Dejours, 2011). No atual contexto de trabalho docente nas universidades públicas do Brasil, tem-se presenciado um modelo de intensificação de trabalho, aumento do ritmo e carga de responsabilidade, devido ao acréscimo de demanda advinda da mercantilização (Coêlho et al, 2016). Esses fatores ganham contornos maiores no caso dos professores substitutos que muitas vezes, como já destacado na categoria anterior, acabam acumulando mais de um vínculo empregatício, aumentando a intensificação e sobrecarga de trabalho.

Assim, nessa categoria foram agrupados os principais fatores percebidos nas entrevistas que se relacionam a saúde mental e ao adoecimento dos professores universitários substitutos. Apesar do foco desse artigo se ater aos dados relativos à saúde mental, é salutar apresentar também os dados obtidos referentes às principais sintomatologias físicas presentes no dia-a-dia desses profissionais.

Foi possível verificar diversos sintomas e indicações de adoecimento dessa categoria profissional, que advém em grande medida dos seguintes fatores: a) a elevada carga de trabalho em sala de aula que demanda tempo para o planejamento, o durante e pós-aula; b) a insegurança diante da fragilidade do contrato de substituto; c) o conciliar mais de um vínculo contratual; d) a intensificação e de todas as exigências por resultados associados ao aumento da produtividade, interposto pela lógica da racionalidade do capitalismo presentes nas instituições de ensino que estão inseridos. Esses fatores trazem então consequências para saúde desses profissionais, conforme destacado nas falas que seguem:

"Reflete no corpo, no sentido que chega um momento em que você, apesar de não ser um trabalho braçal, tem momentos que eu paro e fico muito cansado. Então, as pálpebras começam a tremer, as mãos, a respiração ofegante... E eufui ao médico e ele disse que nada mais é do que excesso de trabalho." (Entrevistado 6)

"Dor de cabeça, dor nas costas, aqueles velhos pontinhos de tensão que todo mundo tem [...] é estresse mesmo, às vezes perda de peso, por que não dá tempo de se alimentar." (Entrevistada 2)

As falas acima apresentam que além de ter que lidar com as exigências interpostas nos dias atuais pela lógica da racionalidade neoliberal inserida no ensino superior público, pautada no produtivismo, na competição e na precariedade (Oliveira, Pereira \& Lima, 2017), o professor substituto ainda tem que lidar com o excesso de trabalho que advém da conciliação de mais de 
um vínculo empregatício, o que influencia de modo direto em sua saúde, influenciando até nos horários de alimentação e lazer.

A precarização advinda dos vínculos temporários com as instituições de ensino, presente na baixa remuneração, nas jornadas mais longas em sala de aula, e na autonomia reduzida em relação ao seu trabalho, somadas a insegurança diante do futuro, ao acúmulo de vínculos empregatícios e a pressão pelo produtivismo acadêmico, acabam levando esses profissionais a desenvolverem vários sintomas frente ao seu exercício profissional. Ao serem questionados sobre o seu estado de saúde, os participantes apesar de não diagnosticados, apontaram várias sintomatologias (físicas e psíquicas) que foram agrupados na Tabela 01 a seguir:

Tabela 01: Sintomatologias frente o exercício da função de docente substituto

\begin{tabular}{c|c}
\hline Físicos & Psíquicos \\
\hline Exaustão & Estresse \\
\hline Queda de cabelo & Tristeza \\
\hline Gastrite & Ansiedade \\
\hline Tremores & Desânimo \\
\hline
\end{tabular}

Fonte: Autores

Os dados apontados acima demonstram que a conjuntura na qual os professores substitutos estão submetidos tem implicado em diversas consequências na saúde desses profissionais. Apesar desses dados se constituírem como sintomas de adoecimento de professores de um modo geral, no caso dos professores substitutos esses sintomas ganham maiores proporções, sobretudo frente ao sentimento de insegurança diante do futuro e à necessidade de possuir mais de um vínculo empregatício, o que difere dos professores efetivos.

A sensação de exaustão foi algo presente em grande parte dos discursos dos participantes. O que demonstra que, diferentemente dos professores efetivos que possuem uma maior estabilidade e não precisam acumular diferentes jornadas de trabalhos, a forma como o trabalho do professor substituto tem se organizado e como o serviço desses profissionais tem sido prestado são elementos que, conforme destaca Dejours (2004a), afetam o funcionamento psíquico dos trabalhadores podendo levá-los ao adoecimento.

Quando se observa mais especificamente os sintomas psíquicos apresentados pelos participantes (o estresse, a ansiedade, os sentimentos de desânimo e tristeza), verifica-se que eles acabam contribuindo para um crescente aumento de transtornos mentais nos professores, 
o que pode vir desencadear no desenvolvimento da síndrome de burnout, transtornos de ansiedade e até depressão (Coêlho et al., 2016; Oliveira, Pereira \& Lima, 2017). E, quando não há um tempo dedicado à recuperação desses profissionais, pode haver agravamento dos sintomas clínicos, os quais podem resultar no afastamento desses profissionais das instituições as quais prestam serviço (Gasparini et al., 2005)

Nesse cenário, percebe-se que as consequências do vínculo de trabalho temporário e todos os seus desdobramentos tem se apresentado como fontes que potencializam o adoecimento (físico e psíquico) desses profissionais, deixando-os mais suscetíveis ao sofrimento psíquico no trabalho.

Entretanto, a abordagem psicodinâmica do trabalho amplia as perspectivas a respeito do trabalho humano, com o entendimento de que o trabalho tanto pode ser causador de sofrimento, como também é gerador de prazer, contribuindo para a saúde do sujeito (Dejours, 2011). Os dados coletados também permitiram captar essas vivências de prazer em relação ao trabalho do professor substituto, as quais se fazem importante para compreender a relação com a saúde mental desses profissionais.

Nessa dinâmica da relação trabalho-saúde mental, percebeu-se que o trabalho como professor substituto também favorece algumas vivências prazerosas à esses profissionais, entre elas destacam-se o contato com diferentes pessoas, a troca de experiências profissionais com outros professores, a realização de estar em sala de aula e o fato de sentirem-se valorizados ao contribuírem com a formação dos alunos para o mercado de trabalho, como é possível verificar nas falas a seguir:

"Apesar de tudo, eu gosto assim... da sala de aula... eu gosto de estar com os alunos, conversar, eu gosto de dar aula, em tudo, eu gosto da interação e a questão da interação com os colegas. A gente tem uma interação muito legal lá na instituição e, assim a gente não tem problema, a gente se ajuda em relação a isso. Acho que é a questão da sala de aula mesmo, que eu gosto muito mesmo." (Entrevistado 05)

"[...] então quando eu vejo que eles estão bem encaminhados, quando eu vejo que eles conseguem emprego e dizem que aprenderam algo comigo." (Entrevistado 06)

Dejours (1986) afirma que o modo como o trabalho se constitui e o significado que tem para os sujeitos irá influenciar no modo como o trabalho é vivenciado. Assim, quando se observa o discurso desses profissionais, percebe-se que ao proporcionar realização profissional, e sentirem-se reconhecidos por ele (Dejours, 2004a; 2012) o trabalho como professor substituto também tem afetado de modo positivo suas vidas, e nesses casos favorecendo a saúde mental desses trabalhadores. 
Além dessas vivências prazerosas no trabalho, para fazer frente às situações de sofrimento/adoecimento destacadas acima, os professores também desenvolvem algumas estratégias defensivas (Dejours, 2004a) em seu cotidiano de trabalho, ponto que será apresentado na categoria seguinte.

\section{As estratégias defensivas}

A utilização de estratégias defensivas por parte dos trabalhadores frente aos constrangimentos da organização de trabalho se constituem como um importante elemento apresentado pela psicodinâmica do trabalho. Para lidar com os sofrimentos causados pelo trabalho, Dejours $(1992 ; 2012)$ aponta que os trabalhadores criam estratégias de defesas para se protegerem de tais situações, as quais podem ser individuais ou coletivas.

No trabalho do professor universitário substituto, algumas estratégias apontadas pelos participantes dizem respeito à autovalorização de seu trabalho, a do entendimento de seu papel no processo de aprendizagem, bem como a busca de auxílio psicológico para lidar com as implicações presentes na atividade docente, conforme se vê nos relatos:

"[...] eu busco me sentir importante no processo, me ver como importante e enxergar, né, de forma concreta mesmo o meu trabalho, os resultados do meu trabalho na formação dos meus alunos." (Entrevistado 06)

"Procurando enxergar mais o lado positivo e, além disso, faço terapia também, [...] que também me ajuda muito a segurar essa onda dá... de estar aqui hoje e talvez. amanhã não estar... E em paralelo, vou distribuindo meu currículo por aí, fazendo meus trabalhos extras, pra não ficar só na dependência aqui da instituição." (Entrevistada 2)

Percebe-se que as estratégias utilizadas são desenvolvidas de modo individual, o que é compreensível dado que nessa pesquisa se coletou dados com professores substitutos em vários departamentos de cursos diferentes em duas universidades públicas, o que torna difícil perceber a elaboração coletiva de estratégias. Esse é também um elemento a ser destacado no trabalho dos professores substitutos: a falta de representação de um coletivo. Diferentemente do trabalho dos professores permanentes, que tem a possibilidade de se organizarem coletivamente de um modo mais efetivo, no caso dos professores substitutos as possibilidades de se estruturarem em um coletivo se torna mais difícil, dificultando o desenvolvimento de estratégias coletivas.

Diante desse cenário, alguns dos participantes afírmaram que não realizam nenhum tipo de enfrentamento frente aos constrangimentos colocados pela organização do trabalho temporário (sobrecarga de aulas, impedimentos na escolha de disciplina, autonomia reduzida, 
insegurança, dificuldades de se constituir um coletivo), como se observa nos seguintes fragmentos:

"Eu não posso fazer nada, entendeu, que substituto não vai adiantar de nada. Então assim, isso é comum a todos substitutos, porque eu converso com os outros também [...] mas a gente não pode fazer nada" (Entrevistado 5)

"Infelizmente a gente é um grito sem voz, que as pessoas não nos escutam, vê a gente sofrer, [...] e ninguém se preocupa com isso "ah é normal, ah é normal esse povo sofrer aí."," (Entrevistado 1)

As falas destacadas apresentam o sentimento de descontentamento e revolta dos participantes ao destacarem a falta de interesse presente nas universidades públicas de se importarem com os professores substitutos, alertando para uma invisibilidade dos mesmos. Ao mesmo tempo, tais posicionamentos também demonstram a postura de fuga adotada por esses profissionais, para não se desgastarem ou adoecerem, poupando energia que demandaria o enfrentamento daquilo que gera sofrimento (Santos, 2009).

Essa postura de fuga pode ter desdobramentos na saúde desses trabalhadores, pois conforme destaca Dejours (2004a), se o profissional não enfrenta as questões que lhe incomodam na organização, como por exemplo, apenas aceitar, não se colocar, não lutar pelos seus direitos, tanto de modo individual como coletivo, sua saúde poderá ser afetada, visto que sua liberdade e seus desejos não são defendidos, o que não ocasiona mudança.

Por outro lado, percebe-se que as instituições de ensino também acabam por não possibilitarem muitos espaços a esses profissionais além da carga horária em sala, o que acaba em grande medida restringindo-os às exaustivas jornadas em sala de aula. Sendo assim, podese entender que o próprio modo como o trabalho e suas regras estão estabelecidas acabam por limitar a criatividade desses profissionais na realização do trabalho como substitutos, o que pode afetar negativamente a saúde mental, indicando assim algum tipo de adoecimento no decorrer do tempo (Dejours, 1986).

\section{CONSIDERAÇÕES FINAIS}

Os dados apresentados nessa investigação demonstram um cenário que muitos professores substitutos estão submetidos nas universidades públicas brasileiras. Os aspectos ligados à organização do trabalho docente acabam levando esses profissionais a uma sobrecarga de trabalho, advinda de uma carga horária maior em sala de aula, com mais disciplinas e mais turmas para lidar com as atividades de planejamento, execução e avaliação das aulas. Atrelado 
a isso, soma-se a insegurança diante do futuro e a falta de autonomia desses profissionais, que não participam do processo de distribuição das disciplinas, encontram dificuldades para desenvolverem projetos de pesquisa ou extensão, e sentem-se excluídos e/ou não acolhidos quando ingressam em muitos dos departamentos/colegiados de cursos.

Os dados levantados também demonstraram a precarização e desvalorização desses profissionais, que além de incutir um sentimento de não reconhecimento, em termos salariais, acabam levando muitos dos professores a assumirem outras atividades em outras instituições (como docente ou não) para complementar a renda pessoal e/ou familiar. Essa dupla (ou tripla) jornada de trabalho acaba repercutindo nas condições de saúde desses trabalhadores, deixandoos mais propensos ao adoecimento físico e mental, sobretudo quando comparado aos professores efetivos que não precisam lidar com o acúmulo de mais de um vínculo empregatício.

Além disso, é possível perceber que a precarização presente nessa forma de trabalho também traz consequências, de um modo mais geral, ao desenvolvimento científico. Inseridos numa ótica de intensificação de trabalho, exaustão e acúmulo de vínculos, falta tempo para que esses profissionais possam dedicar-se às atividades de pesquisa e/ou extensão, bem como uma maior dedicação às atividades de ensino (mais tempo para planejamento, para as atividades pósaula, entre outros), o que pode comprometer a qualidade dos serviços prestados pelos professores substitutos e, portanto, no desenvolvimento científico.

A relação com os alunos também é um elemento que pode ser afetado pela precarização presente nesse tipo de trabalho, uma vez que o acúmulo de muitas disciplinas e turmas em mais de uma instituição, contribui para a impossibilidade de acompanhar o desenvolvimento acadêmico de tantos alunos de um modo mais pontual.

Nesse sentido, faz-se necessário pensar as formas que a presença e a valorização dos professores substitutos estão se dando nas universidades públicas brasileiras, pois como verificado nessa pesquisa, há fortes indícios que a conjuntura na qual estão inseridos traz consequências para a saúde mental desses trabalhadores, sobretudo quando se considera os docentes substitutos da universidade pública estadual, que no caso estudado, ainda lidam com a desvalorização financeira, expressa pelo não pagamento da remuneração referente à titulação.

Os dados referentes a saúde mental dos professores substítutos é algo que necessita ainda ser melhor explorado por novas pesquisas, uma vez que essa população tem crescido no decorrer dos últimos anos em decorrência do cenário que a educação pública superior tem passado no Brasil. Com os cortes orçamentários na educação e a consequente redução na realização de concursos públicos para contratação de novos docentes, presencia-se uma 
defasagem de docentes no quadro de efetivos necessário em cada departamento/colegiado de curso. Assim, tem sido crescente o número de seleções para docentes substitutos em muitas instituições de ensino superior, aumentando o quantitativo desses profissionais, e portanto sendo necessário que mais estudos analisem as condições de trabalho dessa categoria profissional.

A estratégia metodológica adotada nessa pesquisa de abordagem qualitativa levou a uma redução amostral, sendo necessário o desenvolvimento de estudos que possam abranger um maior número de participantes. Além disso, a realidade apresentada foi investigada em apenas um estado da região nordeste, lançando luz para que novos estudos em outros estados e regiões brasileiras possam ser realizados a fim de conhecer ainda mais o trabalho dos professores substitutos em outros contextos.

Outro ponto a ser destacado nessa investigação é que por meio da técnica bola de neve, adotada nesse estudo, não houveram participantes da área de conhecimento das ciências exatas, população que também está sujeita às pressões do produtivismo acadêmico e dos patrocínios da iniciativa privada, muito comum nessa área, por meio do financiamento de projetos universitários.

Por fim, considera-se que apesar das limitações os resultados alcançados nessa pesquisa cumpriram os objetivos aos quais se propunham, trazendo ao centro discussões sobre os aspectos do trabalho desenvolvido por professores universitários substitutos nas instituições de ensino superior públicas, e as relações desse trabalho com a saúde mental desses participantes.

\section{REFERÊNCIAS}

Abrahão, J. I., \& Torres, C. C. (2004). Entre a organização do trabalho e o sofrimento: o papel de mediação da atividade. Production, 14 (3), 67-76. Recuperado de http://www.scielo.br/pdf/prod/v14n3/v14n3a07.pdf

Antunes, R. (2008) A precarização estrutural do trabalho em escala global. In: __. Adeus ao trabalho? Ensaio sobre as metamorfoses e a centralidade do mundo do trabalho. $13^{\mathrm{a}} \mathrm{ed}$. São Paulo: Cortez, p.103-109.

Amaral, G. A., Borges, A. L., \& Juiz, A. P. de M. (2017). Organizaçâo do trabalho, prazer e sofrimento de docentes públicos federais. Caderno de Psicologia Social do Trabalho, 20(1), 15-28. Recuperado de http://pepsic.bvsalud.org/pdf/cpst/v20n1/a02v20n1.pdf 
Aquino, C. A. B., Moita, D. S. de, Correa, M., \& Souza, K. O. (2014). O fenômeno dá precarização do trabalho e dá flexibilização no âmbito da universidade pública brasileira: o caso de dois professores substitutos. Revista de Pensamiento e Investigación Social, 14(1), 173- 193. Recuperado de http://www.redalyc.org/articulo.oa?id=53730481008

Braga, D. K. C. S., \& Oliveira, L. S. da S. de. (2015). A precarização do trabalho nas universidades e a saúde do trabalhador: uma análise preliminar. Rede de Estudos do Trabalho, [s.i], 17, 22-42. http://www.estudosdotrabalho.org/A2RRET17.pdf

Cericato, I. L. (2016). A profissão docente em análise no Brasil: uma revisão bibliográfica. Revista Brasileira de Estudos Pedagógicos, 97(246). Recuperado de http://www.scielo.br/pdf/rbeped/v97n246/2176-6681-rbeped-97-246-00273.pdf doi:10.1590/S2176-6681/373714647

Coêlho, R. D. F. N., Sousa, F. L. de, \& Coêlho, I. N. (2016). A saúde de professores universitários no sertão nordestino-Brasil: investigando suas características clínicocomportamentais. Mneme-Revista de Humanidades, 17(38), 83-102. Recuperado de https://periodicos.ufrn.br/mneme/article/view/9552/7074

Dejours, C. (1986). Por um novo conceito de saúde. São Paulo: Revista brasileira de saúde ocupacional, 14(54), 7-11.

Dejours, C. (1992). A loucura do trabalho: estudo de psicopatologia do trabalho. São Paulo: Cortez - Oboré, 1, 9-11.

Dejours, C. (2004a). Addendum: Da psicopatologia à psicodinâmica do trabalho. In: Lancman, S.; Sznelwar, L. (Orgs.) Christophe Dejours: da psicopatologia à psicodinâmica do trabalho (pp. 47-104). Rio de Janeiro: Fiocruz, Brasília: Editora Paralelo 15.

Dejours, C. (2004b). Subjetividade, trabalho e ação. Revista Produção, 14 (3), 27-34.

Dejours, C. (2011). Psicopatología del trabajo - Psicodinámica del Trabajo. Laboreal, 7(1), 13-16.

Dejours, C. (2013). Sublimação, entre sofrimento e prazer no trabalho. Revista Portuguesa de Psicanálise, v. 33, n. 2, 9-28.

Dejours, C; Dessors, D. \& Desriaux, F. (1993). Por um trabalho, fator de equilíbrio. Revista de Administração de Empresas, 33(3), 98-104.

Forattini, C. D., \& Lucena, C. A. (2015). Adoecimento e sofrimento docente na perspectiva da precarização do trabalho. Laplage em Revista, 1(2), 32-47. Recuperado de http://www.laplageemrevista.ufscar.br/index.php/lpg/article/view/19/369 doi:10.24115/S2446-622020151219

Gasparini, S. M., Barreto, S. M., \& Assunção, A. Á. (2005). O professor, as condições de trabalho e os efeitos sobre sua saúde. Educação e pesquisa, 31(2), 189-199. Recuperado de http://www.scielo.br/pdf/ep/v31n2/a03v31n2.pdf 
Gorzoni, S. P., \& Davis, C. L. F. (2017). O conceito de profissionalidade docente nos estudos mais recentes. Cadernos de Pesquisa, 47(166), 1396-1413. Recuperado de http://www.scielo.br/pdf/cp/v47n166/1980-5314-cp-47-166-1396.pdf

Laville, C., \& Dionne, J. (1999). Das informações à conclusão. In C. Laville, \& J. Doinne (Orgs), A construção do saber:manual de metodologia da pesquisa em ciências humanas. Porto Alegre: Artmed.

Locatelli, C. (2017). Os professores no ensino superior brasileiro: transformações do trabalho docente na última década. Revista Brasileira de Estudos Pedagógicos, 98(248). Recuperado de http://rbep.inep.gov.br/index.php/rbep/article/view/2815/pdf doi:10.24109/2176-6681.rbep.98i248.2815

Martins, A. A. V. (2009). Vivências de prazer e sofrimento no trabalho docente: um estudo em uma instituição de ensino superior de Belo Horizonte (Dissertação de mestrado). Faculdade Novos Horizontes, Belo Horizonte, MG, Brasil. Recuperado de: http://unihorizontes.br/novosite/banco_dissertacoes/120520111545574507.pdf

Moré, C. L. O. O. (2015). A "entrevista em profundidade" ou "semiestruturada", no contexto da saúde. Atas CIAIQ-Investigação Qualitativa em Ciências Sociais, 3, 126-131. Recuperado de https://proceedings.ciaiq.org/index.php/ciaiq2015/article/view/158/154

Moreira, D. de A., Tibães, H. B. B., \& Brito, M. J. M. (2018). Prazer e sofrimento de docentes na pós-graduação stricto sensu em enfermagem. Rev Rene - Revista da Rede de $\begin{array}{lllll}\text { Enfermagem do } & \text { Nordeste, } & \text { Recuperado }\end{array}$ http://periodicos.ufc.br/rene/article/view/33328/pdf

Minayo, M.C.S. (2006). O desafio do conhecimento: Pesquisa qualitativa em saúde. São Paulo - Rio de Janeiro: Hucitec - Abrasco.

Oliveira, A. D. S. D., Pereira, M. de S., \& Lima, L. M. de (2017). Trabalho, produtivismo e adoecimento dos docentes nas universidades públicas brasileiras. Psicologia Escolar $e$ Educacional, 21(3), 609-619. Recuperado de http://www.scielo.br/pdf/pee/v21n3/21753539-pee-21-03-609.pdf

Rates, A. C. F., \& Léda, D. B. (2016). A saúde no trabalho de professores substitutos de uma universidade federal brasileira: entre vivências de prazer e sofrimento. Universidade Pedagógica Nacional. http://redeestrado.org/xi_seminario/pdfs/eixo6/134.pdf Recuperado de

Resolução $n^{\circ} 466$, de 12 de dezembro de 2012. A presente Resolução incorpora, sob a ótica do indivíduo e das coletividades, referenciais da bioética, tais como, autonomia, não maleficência, beneficência, justiça e equidade, dentre outros, e visa a assegurar os direitos e deveres que dizem respeito aos participantes da pesquisa, à comunidade científica e ao Estado. http://bvsms.saude.gov.br/bvs/saudelegis/cns/2013/hes0466_12 12 2012.html

Santino, T. A., Tomaz, A. F., \& Lucena, N. M. G. (2017). Influência da Fadiga Ocupacional na Capacidade para o Trabalho de Professores Universitários. Ciencia \& trabajo, 19(59), 8690. Recuperado de https://scielo.conicyt.cl/pdf/cyt/v19n59/0718-2449-cyt-195900086.pdf 
Santos, C. D. C., Pereira, F., \& Lopes, A. (2018). Experiências da Gestão Acadêmica da Docência Universitária. Educação \& Realidade, 43(3), 989-1008. Recuperado de http://www.scielo.br/pdf/edreal/2018nahead/21756236edreal2175623674106.pdf doi: 10.1590/2175-623674106

Santos, G. B. D. (2009). Os professores e seus mecanismos de fuga e enfrentamento. Trabalho, educação e Saúde, 7(2), 285-304. Recuperado de http://www.scielo.br/pdf/tes/v7n2/06.pdf doi: $10.1590 / 2175-623674106$

Silveira, D. T., Córdova, F. P. (2009). A pesquisa científica. In T. E. Gerhardt, \& D.T. Silveira. Métodos de pesquisa. Porto Alegre: Ufrgs, Cap. 2, p. 35. Recuperado de https://books.google.com.br/books?hl=pt-

BR\&lr=\&id=dRuzRyEIzmkC\&oi=fnd \&pg $=$ PA9\&dq=pesquisa + descritiva\&ots=92Q9Z0 mvJJ\&sig=ObHK3m4lEMbniEPkMF4LNxuVhQY\#v=onepage\&q==false

Vigotski, L. (1991). A formação social da mente. São Paulo: Martins Fontes.

Vilela, E. F., Garcia, F. C., \& Vieira, A. (2013). Vivências de prazer-sofrimento no trabalho do professor universitário: estudo de caso em uma instituição pública. Revista Eletrônica de Administração, $19(2)$ 517-540.

Recuperado de http://www.scielo.br/pdf/read/v19n2/v19n2a10.pdf

Vinuto, J. (2014). A amostragem em bola de neve na pesquisa qualitativa: um debate em aberto. Temáticas, $22(44)$, 203-220. Recuperado de https://www.ifch.unicamp.br/ojs/index.php/tematicas/article/view/2144 